\title{
Evaluation of nano-mechanical properties and morphology of filled polypropylene modified by irradiation
}

\author{
Martin Ovsik ${ }^{1 *}$, Michal Stanek ${ }^{1}$, and Martin Reznicek ${ }^{1}$ \\ ${ }^{1}$ Tomas Bata University in Zlin, TGM 5555, 76001 Zlin, Czech Republic
}

\begin{abstract}
This paper describes the effect of electron beam irradiation on the surface properties (nanoindentation test) of glass fiber filled polypropylene (30\%). These nano-mechanical properties were measured by the DSI (Depth Sensing Indentation) method on samples which were non-irradiated and irradiated by different doses of the $\beta$ - radiation (33, 66 and $99 \mathrm{kGy}$ ). The purpose of the article is to consider to what extent the irradiation process influences the resulting nano-mechanical properties measured by the DSI method. The polypropylene tested showed significant changes of indentation hardness and modulus. The best results were achieved by irradiation at doses of $99 \mathrm{kGy}$ (increase about 35\%) by which the highest nano-mechanical properties of filled polypropylene were achieved. These changes were examined and confirmed by X-ray diffraction and Gel content.
\end{abstract}

\section{Introduction}

Polypropylene (PP) is a stereospecific polymer prepolyamydered by polymerization using an organometallic catalyst system. Commercial polypropylenes have up to $95 \%$ isotactic content, which means that pendant methyl groups are almost all on the same side of the chain.

When polypropylene is exposed to ionizing radiation, free radicals are formed and these cause chemical changes. Since PP is highly crystalline, these radicals are relatively immobile, and consequently may not be available for reaction for long periods of time.

As with other polyolefins, upon irradiation the free radicals are formed along with evolution of hydrogen gas. If the radical is formed on the pendant methyl, the resulting reaction is cross-linking. However, if the radical is formed in the main chain, the chain end may react with hydrogen, thus causing an irreversible scission. Although the processes of chain scission and cross-linking occur simultaneously, and even though the net effect is crosslinking, the overall effect is the loss of mechanical strength. [1-3].

Electron beams ( $\beta$-rays) generated by accelerators are monoenergetic and the absorbed dose is greatest just below the surface of the irradiated material and falls rapidly at greater depths in the material (Figure 1). The energy range of electron beams used in radiation processing is from 0.15 to $10 \mathrm{MeV}$. Compared with gamma irradiation, electron accelerators have advantages of higher power and directional beams. The time of irradiation by $\beta$-rays is in seconds. The limited

\footnotetext{
* Corresponding author: ovsik@ft.utb.cz
}

penetrating power of electron beams means that they are mainly used for irradiating relatively thin objects like wires and cable insulation [1-4].

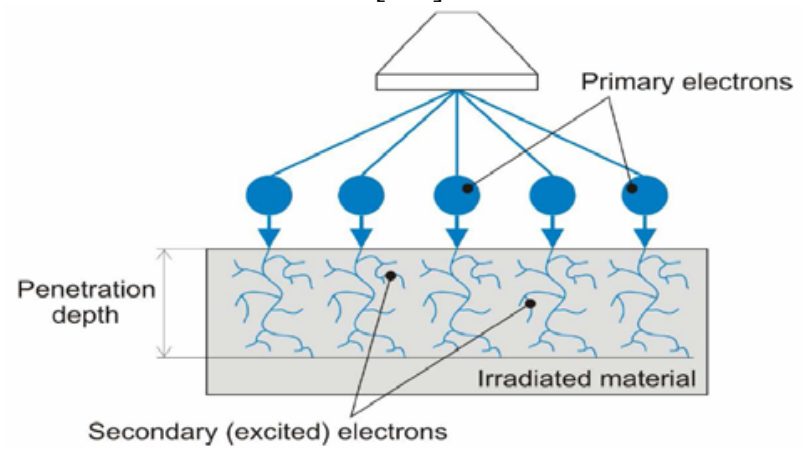

Fig. 1. Radiation crosslinking by electrons rays [2].

Common polypropylene, when exposed to the effect of the radiation cross-linking, degrades and its mechanical properties deteriorate. Using cross-linking agent TAIC (triallyl isocyanurate) produces a crosslinking reaction inside the polypropylene structure. The utility properties of polypropylene improve when the non-crystalline part of polypropylene is cross-linked. [3-5].

The aim of this paper is to study the effect of ionizing radiation with different doses, on nano-mechanical properties of polypropylene filled by $30 \%$ glass fiber (PP $30 \mathrm{GF}$ ) and compare these results with those of nonirradiated samples. The study is carried out due to the ever-growing employment of this type of polymer (PP 30GF). 


\section{Experimental}

\subsection{Material}

For this experiment polypropylene PP PTS - Crealen EP$865 \mathrm{HS}-\mathrm{M} 0083$ filled by $30 \%$ glass fibers (PP 30GF), that were supplied by PTS Plastics Technology Service, Germany was used. The material already contained the special cross-linking agent TAIC - triallyl isocyanurate (6 volume \%), which should enable subsequent crosslinking by ionizing $\beta$-radiation.

\subsection{Sample preparation}

The samples were made using the injection molding technology on the injection molding machine Arburg Allrounder $470 \mathrm{H}$. Processing temperature $210-230{ }^{\circ} \mathrm{C}$, mold temperature $55{ }^{\circ} \mathrm{C}$, injection pressure $90 \mathrm{MPa}$, injection rate $50 \mathrm{~mm} / \mathrm{s}$.

\subsection{Irradiation}

The prepared specimens were irradiated with doses of 0 , 33, 66 and 99 kGy at BGS Beta-Gamma Service GmbH \& Co. KG, Germany.

\subsection{X-ray diffraction.}

X-ray diffraction patterns were obtained using a PAN alytical X-pert Prof X-ray diffraction system (Netherlands). The $\mathrm{CuK} \alpha$ radiation was Ni-filtered. The scans $\left(4.5^{\circ} 2 \mathrm{Q} / \mathrm{min}\right)$ in the reflection mode were taken in the range $5-30 \circ 2 \Theta$. The sample crystallinity $\mathrm{X}$ was calculated from the ratio of the crystal diffraction peaks and the total scattering areas.

\subsection{Nano-indentation}

Nano-indentation test were performed using a Nanoindentation tester (Figure 2), CSM Instruments (Switzerland) according to the CSN EN ISO 14577. The tip is made of diamond having the shape of a cube corner (Vickers). In the present study, the maximum load used was $100 \mathrm{mN}$ and loading rate (and unloading rate) was $200 \mathrm{mN} / \mathrm{min}$. A holding time was $90 \mathrm{~s}$ at the indentation and $21600 \mathrm{~s}$ at the creep.

The indentation hardness $\left(\mathrm{H}_{\mathrm{IT}}\right)$ was calculated as maximum load $\left(\mathrm{F}_{\max }\right)$ to the projected area of the hardness impression $\left(\mathrm{A}_{\mathrm{p}}\right)$ and the indentation modulus $\left(\mathrm{E}_{\mathrm{IT}}\right)$ is calculated from the Plane Strain modulus $\left(\mathrm{E}^{*}\right)$ using an estimated sample Poisson's ratio (v) according to $[4-7]$ :

$$
\begin{gathered}
H_{I T}=\frac{F_{\max }}{A_{p}} \\
E_{I T}=E^{*} \cdot\left(1-v_{s}{ }^{2}\right)
\end{gathered}
$$

Measurement of all above mentioned properties was performed 10 times to ensure statistical correctness.

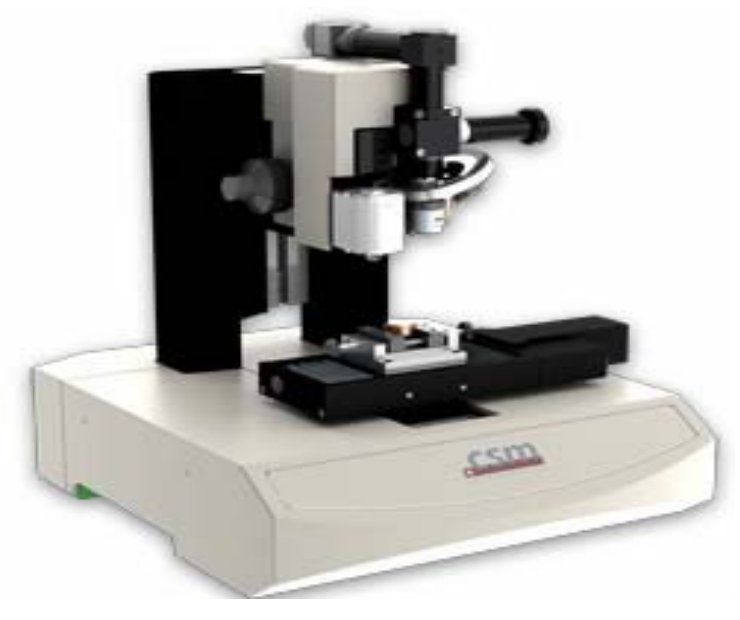

Fig. 2. Nano-indentation tester.

\section{Results and discussion}

\subsection{X-ray diffraction}

Figure 3 shows typical X-ray diffraction of the nonirradiated and irradiated polypropylene. The results of the crystallinity for non-radiated and irradiated PP 30GF are shown in the Fig. 4. The values measured show some heterogeneity of the crystallinity at individual radiation doses. When applying $\beta$-radiation the structure of PP $30 \mathrm{GF}$ undergoes decrease of the crystalline phase.

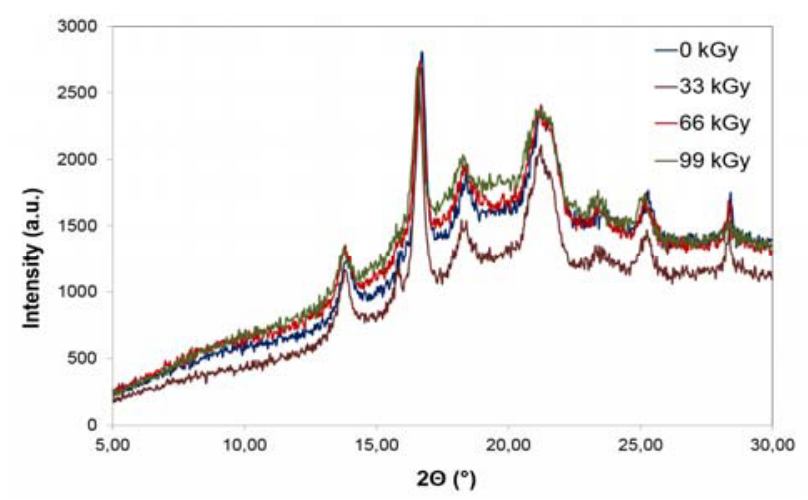

Fig. 3. $\mathrm{X}$ - ray diffractograms of PP $30 \mathrm{GF}$.

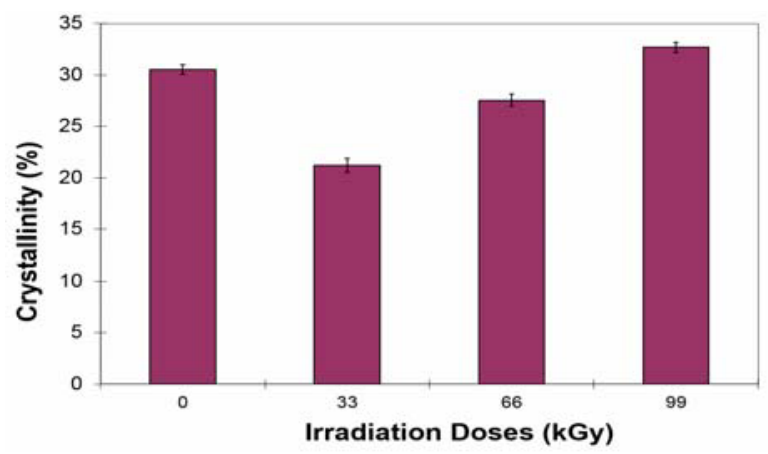

Fig. 4. Crystallinity of PP 30GF. 
The smallest value of crystallinity was found in the case of the PP $30 \mathrm{GF}$ irradiated at the dose of $33 \mathrm{kGy}$. On the contrary the highest value of crystallinity (Fig. 4) was measured at non-irradiated and the irradiated at dose of 99 kGy.

The process of irradiation causes physical and chemical changes in the structure of PP 30GF. They are mainly changes of crystalline and amorphous phase. The measurement results show clearly that as the irradiation dose increases, the crystallinity decreases. During the amorphous phase cross-linking occurs which results in creation of very solid areas as well as considerable growth of nano-hardness values. Higher irradiation doses do not cause greater cross-linking but rather disruption of links resulting in degradation of the irradiated material.

\subsection{Gel Content}

Gel content showed the highest values at radiation dose of $66 \mathrm{kGy}$ at which it reached $66.8 \%$ degree of crosslinking. Specimens irradiated by $99 \mathrm{kGy}$ radiation dose showed very similar value $67 \%$ degree of cross-linking (Fig. 5).

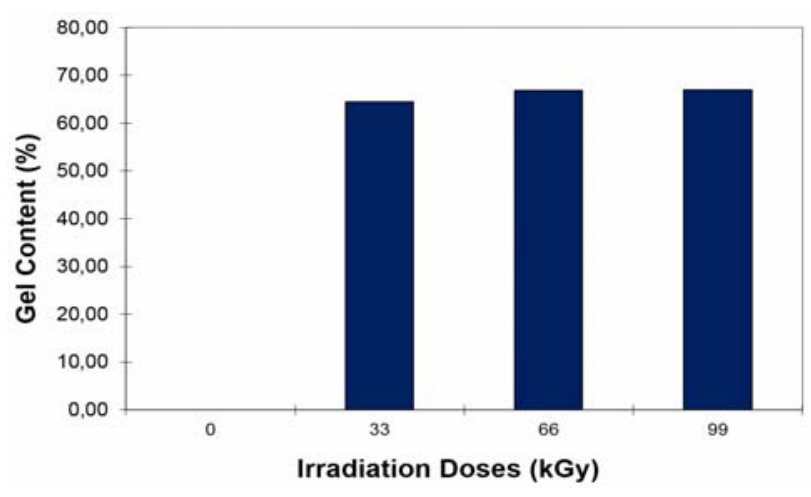

Fig. 5. Gel content of PP 30GF.

\subsection{Nano-indentation test}

Radiation cross-linking creates changes in the PP $30 \mathrm{GF}$ structure by creating $3 \mathrm{D}$ net. Beta radiation gradually penetrates more deeply into the PP $30 \mathrm{GF}$ structure through the surface layer. The surface layer undergoes changes which have a considerable influence on the nano-mechanical properties of PP 30GF.

The Figure 6 show a very important correlation between the force and the depth of the indentation. The correlations provide very valuable information on the behavior of tested material and the modified surface layer. The correlation between the force and the depth of the indentation in PP 30GF also proved very interesting. It demonstrated the influence of radiation on the change of nano-mechanical properties in the surface layer of specimens. The non-irradiated material showed low hardness as well as increasing impression of the indenter in the surface layer. On the contrary, the irradiated PP 30GF showed considerably smaller depth of the impression of the indenter which can signify greater resistance of this layer to wear.

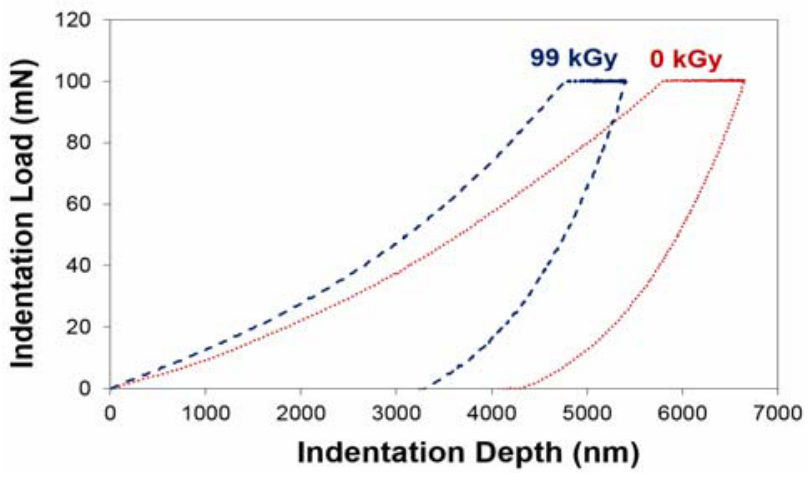

Fig. 6. Indentation characteristic of irradiated PP 30GF.

The greatest values of nano-hardness test were obtained for PP $30 \mathrm{GF}$ irradiated with dose of $99 \mathrm{kGy}$ as is apparent in Table 1.

Table 1. Summary of measured values.

\begin{tabular}{|c|c|c|c|c|}
\hline Irradiation doses & 0kGy & 33kGy & 66kGy & 99kGy \\
\hline HIT (Mpa) & 130.43 & 146.59 & 171.87 & $\mathbf{1 7 5 . 8 7}$ \\
\hline EIT (Gpa) & 2.43 & 2.95 & 3.34 & $\mathbf{3 . 2 1}$ \\
\hline Wel (uJ) & 0.09 & 0.08 & 0.07 & $\mathbf{0 . 0 8}$ \\
\hline Wpl (uJ) & 0.22 & 0.22 & 0.19 & $\mathbf{0 . 1 9}$ \\
\hline CIT (\%) & 16.27 & 15.10 & 14.95 & $\mathbf{1 5 . 5 2}$ \\
\hline Gel Content (\%) & 0.00 & 64.40 & 66.80 & $\mathbf{6 7 . 0 0}$ \\
\hline
\end{tabular}

Nano-indentation test of PP 30GF modified by beta radiation showed that the highest values of indentation hardness was found for PP 30GF modified by the radiation dose of $99 \mathrm{kGy}\left(\mathrm{H}_{\mathrm{IT}}=175.9 \mathrm{MPa}\right)$. The smallest value of indentation hardness was found for nonirradiated PP $30 \mathrm{GF}\left(\mathrm{H}_{\mathrm{IT}}=130.4 \mathrm{MPa}\right)$. The increase of indentation hardness value for PP $30 \mathrm{GF}$ irradiated by the dose of $99 \mathrm{kGy}$ was by 35\% (Figure 7) in comparison with the non-irradiated PP 30GF.

Similar behaviour was found for indentation modulus $\mathrm{E}_{\mathrm{IT}}$ according to Oliver and Pharr method (see Figure 8), which also increases with increasing irradiated doses. Values of stiffness showed the highest value 3.2 $\mathrm{GPa}$ at $99 \mathrm{kGy}$ radiation dose, while the lowest stiffness value 2.4 GPa was found in non-irradiated PP 30GF. This represents increase in indentation modulus by $33 \%$.

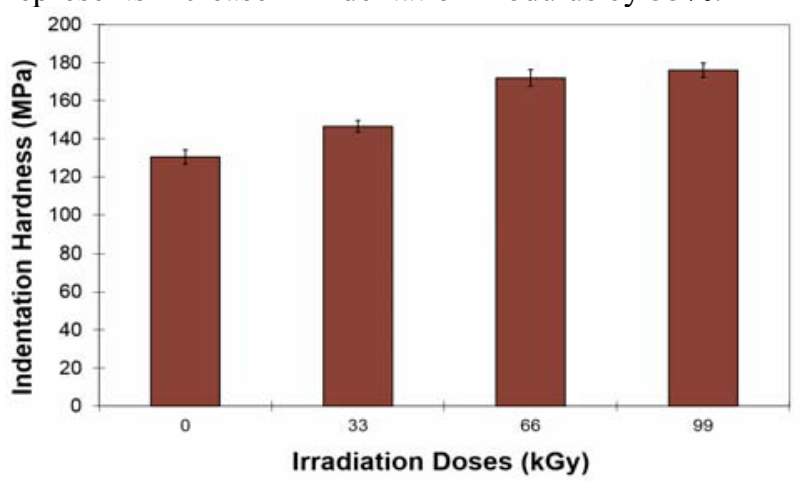

Fig. 7. Indentation hardness $\left(\mathrm{H}_{\mathrm{IT}}\right)$. 


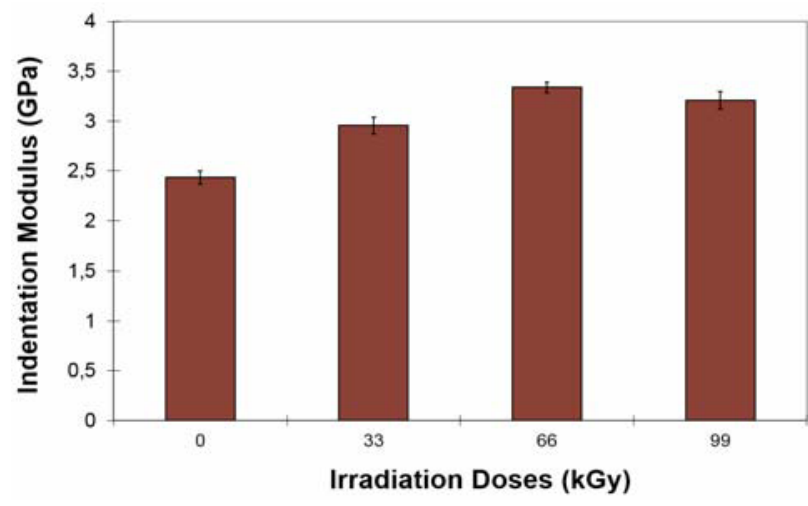

Fig. 8. Indentation modulus ( $\left.\mathrm{E}_{\mathrm{IT}}\right)$.

Very important values were found for indentation creep $\left(\mathrm{C}_{\mathrm{IT}}\right)$. The lowest value of indentation creep was measured at radiation dose of $99 \mathrm{kGy}\left(\mathrm{C}_{\mathrm{IT}}=15.5 \%\right)$. The highest indentation creep value measured at nonirradiated PP $30 \mathrm{GF}\left(\mathrm{C}_{\mathrm{IT}}=16.2 \%\right)$. Decrease in creep values was $5 \%$ for irradiated PP $30 \mathrm{GF}$ compared to the non-irradiated one as is seen at Figure 9.

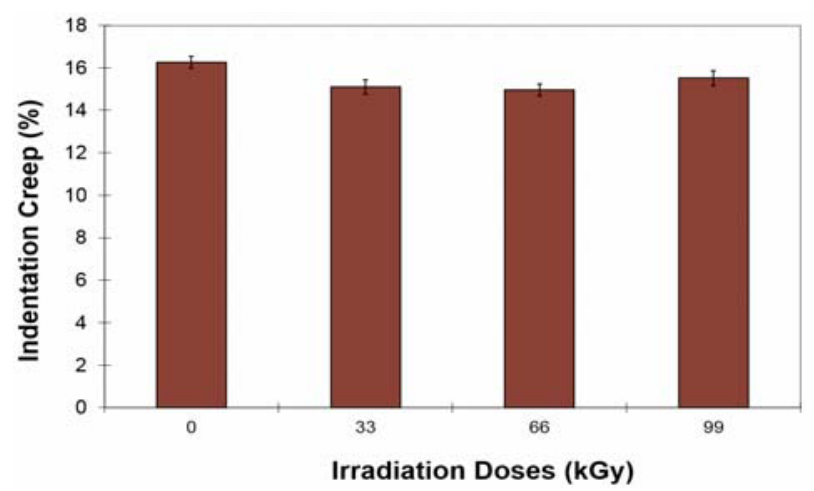

Fig. 9. Indentation creep $\left(\mathrm{C}_{\mathrm{IT}}\right)$.

Interesting results were found for elastic and plastic part of deformation work. The highest value of elastic and plastic deformation work was measured for nonirradiated PP 30GF. The lowest value at both deformation work was found when the highest value of radiation dose of $99 \mathrm{kGy}$ was applied (Figure 10).

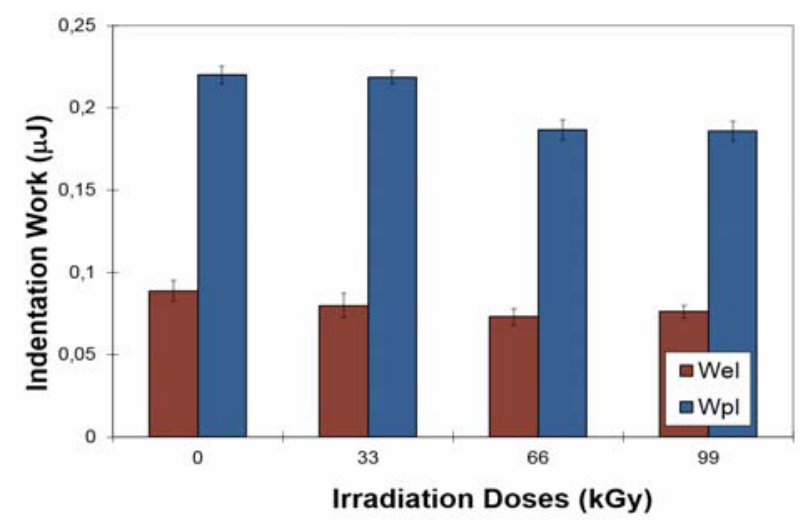

Fig. 10. Elastic and plastic part of deformation work.
Higher radiation dose does not influence significantly the nano-mechanical properties. An indentation hardness increase of the surface layer is caused by irradiation cross-linking of the tested specimen. A closer look at the nano-hardness results reveals that when the highest radiation doses are used, nano-mechanical properties decreases which can be caused by radiation induced degradation of the material.

\section{Conclusion}

Radiation, which penetrated through specimens and reacted with the cross-linking agent, gradually formed cross-linking (3D net), first in the surface layer and then in the total volume, which resulted in considerable changes in specimen behaviour.

The experimental study showed that glass fibber filled polypropylene modified by beta radiation doses of 0,33 , 66 and $99 \mathrm{kGy}$ showed considerable increase of some nano-properties. In terms of nano-mechanical properties, the values of nano-hardness of surface layer increased by $35 \%$ at radiation dose of $99 \mathrm{kGy}$, stiffness of surface nano layer by 33\% (99 kGy). Nano-creep values dropped in irradiated PP $30 \mathrm{GF}$ from $16.2 \%$ to $15.5 \%$ (99 kGy). Improvement of nano-mechanical properties of radiated PP 30 GF has a great significance also for industry. The modified polypropylene shifts to the group of materials which have considerably better properties. Its creep and other nano-mechanical properties make PP 30GF ideal for a wide application in the areas where higher resistance to wear, creep are required. Commonly manufactured PP 30GF can hardly fulfil these criteria.

\section{Acknowledgment}

This paper is supported by the internal grant of TBU in Zlin No. IGA/FT/2017/010 funded from the resources of specific university research and by the Ministry of Education, Youth and Sports of the Czech Republic within the National Sustainability Programme project No. LO1303 (MSMT-7778/2014) and also by the European Regional Development Fund under the project CEBIATech No. CZ.1.05/2.1.00/03.0089.

\section{References}

1. J.G. Drobny, CRC Press, (2003)

2. M. Ovsik, L. Hylova, D. Manas, M. Manas, M. Stanek, M, MATEC Web of Conferences, 76, (2016)

3. O. N. Tretinikov, S. Ogata, Y. Ikada, Polymer 39, 24 (1998)

4. G. Zamfirova, V. Gaydarov, T. Zaharescu, L. G. Silva, Chemicke Listy 104 (2010)

5. W.C. Oliver, G.M. Pharr, J. Mater. Res., 19. (2004)

6. J. Dobransky, et al. Metalurgija. 54, 3 (2015)

7. G. M. Pharr, Materials Science and Engineering (1998) 